\title{
Medical outcome after immediate computed tomography or admission for observation in patients with mild head injury: randomised controlled trial
}

Jean-Luc af Geijerstam, Sven Oredsson, Mona Britton, for the OCTOPUS Study Investigators

\begin{abstract}
Objective To compare immediate computed tomography during triage for admission with observation in hospital in patients with mild head injury.

Design Multicentre, pragmatic, non-inferiority randomised trial. Setting 39 acute hospitals in Sweden.

Participants 2602 patients (aged $\geq 6$ ) with mild head injury. Interventions Immediate computed tomography or admission for observation.

Main outcome measure Dichotomised extended Glasgow outcome scale $(1-7 v 8)$. The non-inferiority margin was 5 percentage points.

Results At three months, 275 patients (21.4\%) in the computed tomography group had not recovered completely compared with $300(24.2 \%)$ admitted for observation. The difference was -2.8 percentage points, non-significantly in favour of computed tomography $(95 \%$ confidence interval $-6.1 \%$ to $0.6 \%$ ). The worst outcomes (mortality and more severe loss of function) were similar between the groups. In the patients admitted for observation, there was a considerable delay in time to treatment in those who required surgery. None of the patients with normal findings on immediate computed tomography had complications later. Patients' satisfaction with the two strategies was similar.

Conclusions The use of computed tomography in the management of patients with mild head injury is feasible and leads to similar clinical outcomes compared with observation in hospital.

Trial registration ISRCTN81464462.
\end{abstract}

\section{Introduction}

Optimal management of patients with mild head injury in the emergency department is still under debate. There is no consensus regarding guidelines, and clinical practice shows wide variation. ${ }^{1-3}$ No randomised controlled trial has compared different strategies for acute management. ${ }^{4-7}$

Observation in hospital is often standard practice, and the addition of computed tomography has recently become more common. Even in patients with normal findings on computed tomography, admission remains common practice, ${ }^{2}{ }^{9}$ probably because of the risk of missing severe complications and the medicolegal implications. Consistent use of computed tomography during triage for admission might relieve the strain on health services. ${ }^{10}$ Estimates indicate that it could lead to more than 500000 fewer admissions annually in the United States, thus reserving hospital beds for patients with greater needs. ${ }^{9}$

Our own systematic review of the literature as well as a recent one from the World Health Organization suggest that a strategy based on computed tomography is no better or worse for managing mild head injury than a strategy based on observation in hospital. ${ }^{112}$ Some model studies indicate that use of computed tomography reduces costs. ${ }^{10}$ Early diagnosis followed by rapid treatment is another potential advantage. ${ }^{13-16}$ Detection of minor intracerebral injuries that would otherwise go undetected may increase the number of surgical procedures. We tested the hypothesis that a management strategy based on computed tomography and early discharge is no worse for outcome and is less expensive than a strategy based on observation in hospital. ${ }^{17}$ The cost analysis is in an accompanying paper. ${ }^{18}$

\section{Methods}

Definitions

We defined mild head injury as loss of consciousness or amnesia, or both, in patients with normal neurological findings (normal pupillary response, sensibility, reflexes, and response on motor examination) and a Glasgow coma scale (GCS) score of 15 as determined by the attending physician at the patient's arrival in the emergency department after head trauma. ${ }^{19}$

The results of computed tomography were considered abnormal if there were signs of an acute traumatic injury (haemorrhage, oedema, skull fracture). Scans showing only extracranial injury were not considered pathological nor were findings not correlated with the acute head injury.

A complication was defined as deterioration due to the head injury that necessitated neurosurgical intervention, medical treatment, or intensive care. We also included subsequent readmission because of the head injury.

\section{Eligibility and study setting}

Patients aged $\geq 6$ with mild head injury who attended for acute care at any of the participating centres were assessed for eligibility (assessment of outcome is difficult in children aged $<6$ ). The eligibility criteria were head trauma within the past 24 hours; confirmed or suspected loss of consciousness or amnesia, or both; normal results on neurological examination; Glasgow coma score of 15 , and no associated injuries that required admission. Eligible patients received oral and written informa-

The details of investigators, committee members, and other study personnel are on bmj.com. 
tion about the study and gave their written consent to participate. For children consent was obtained from a parent or carer. The Swedish national health and pharmaceutical insurance plan covered all patients included in the study.

In Sweden, current practice is to admit patients with mild head injury for observation. Each year the admission rate is around 191/100 000. About a fifth also receive computed tomography. ${ }^{20}$ Of the 75 emergency departments in Sweden, 39 participated in the study, representing hospitals of all sizes and all parts of the country. A physician and nurse at each participating centre were responsible for the study.

An independent safety committee reviewed data on the main outcome at given intervals and received reports within one week of all deaths and severe complications. The safety committee had the authority to terminate the study early and had decided internally on the rules for termination.

\section{Randomisation}

Physicians at the participating emergency departments randomised patients to immediate computed tomography or observation in hospital. Randomisation was carried out by computer generated sequences stratified by centre in blocks of 24 with the restriction that the balance be no worse than in a sequence of a block of six. Assignments were concealed in sequentially numbered, opaque, sealed envelopes kept by the investigators.

A central trial unit continuously checked and monitored all study data. All coded data were checked to ensure consistency with the original documents. Data were stored safely with limited access. We visited participating centres to ensure that randomisation protocols and other study instructions were properly followed.

\section{Interventions}

Computed tomography strategy-Patients received computed tomography after randomisation. Scans were reported and interpreted according to local clinical practice. If the scan was interpreted as normal, the patient was discharged home. Attending physicians could admit patients, despite normal findings, for other medical or social reasons. All such events and decisions, including the date and hour they occurred, were noted in the case report form. Local guidelines were used in managing complications.

Observation strategy-Patients were admitted for observation as inpatients according to local guidelines. The attending physician could decide to perform computed tomography if this seemed to be clinically necessary. Results were reported and interpreted according to local clinical practice. All interventions, including the date and hour they occurred, were noted in the case report form. Local guidelines were used in managing complications.

\section{Outcome analysis}

We used the extended Glasgow outcome scale (GOS-E), through a postal questionnaire, to assess the outcomes of all randomised patients three months after the injury. ${ }^{21}{ }^{22}$ Patients were asked about their satisfaction with the care received (four alternatives: satisfied, quite satisfied, not satisfied, uncertain). We used reminders and telephone contacts to minimise loss to follow-up. We searched the national population register to rule out complications in patients who could not be traced and hospital care registers of all neurosurgical clinics in Sweden for readmittances and operations. ${ }^{17}$

End points-Our primary end point was outcome according to a dichotomised extended Glasgow outcome score three months after the injury (8 (fully recovered) $v 1-7$ (not fully recov- ered)). To ensure an even distribution among patients with the most severe disabilities, our secondary end points were the same scores dichotomised in six other possible ways (see table 2).

Blinding-Allocation to study group was completely concealed but the patients and study personnel were obviously aware of the allotted strategy. Information used for the Glasgow outcome assessment at three months was self reported by the patients. Two members of the study group and two external reviewers performed a blinded assessment of cause of death and complications. Disagreement was resolved by consensus. During the study, the safety committee had access to unblinded data but had no contact with study participants or the central trial unit.

\section{Sample size}

The study was planned as a non-inferiority study. We considered a difference of 5 percentage points to the disadvantage of computed tomography as the limit for acceptability. From previous studies we estimated that about a quarter of the patients would have a Glasgow outcome score 1-7-that is, be less than fully recovered-at the three month follow-up. ${ }^{23-25}$ With a sample size of 2000 patients the study would have $80 \%$ power to get a one sided $95 \%$ confidence interval that excluded the non-inferiority limit-that is, to show that computed tomography is not inferior to observation in hospital if the true probabilities of Glasgow outcome score 1-7 are 0.25 in both groups. We aimed to randomise 2500 patients to allow for losses to follow-up.

\section{Statistical analysis}

We analysed all data according to a pre-established analysis plan, which prescribed intention to treat analyses. For the primary analysis we have shown a one sided $95 \%$ confidence interval. Thereafter, we used two sided 95\% confidence intervals. Although not prescribed in the study plan, we also subjected the Glasgow outcome data to a rank sum test.

\section{Results}

From May 2001 through January 2004, physicians at the participating departments randomised 2602 patients: 1316 to computed tomography and 1286 to observation in hospital (figure).

Table 1 summarises the characteristics of the two study groups. Participants had a mean age of 31.5 years (SD 22.2), and the mean time from injury to randomisation was 2.3 hours. Treatment groups were well balanced with respect to patients' characteristics, time between injury and randomisation, and hospital category.

All but 90 patients (3.5\%) received the allocated treatment; 24 patients allocated to computed tomography did not receive it, and 66 patients in the observation group were not admitted. As expected, and as allowed by the study protocol, some additional investigations occurred in each group; 117 (8.9\%) patients randomised to computed tomography were also admitted for observation, and $111(8.6 \%)$ randomised to observation also received computed tomography.

\section{Outcome at follow-up}

At the three month follow-up we obtained complete data on the extended Glasgow outcome scale for 2523 patients $(97.0 \%)$ and partial data from 67 (total $2590(99.6 \%)$ ). At follow-up, 275 patients $(21.4 \%)$ in the computed tomography group and 300 $(24.2 \%)$ in the observation group had not recovered completely. The difference $(-2.8 \%$, one sided $95 \%$ confidence interval $\leq 0.03 \%$, two sided confidence interval $-6.1 \%$ to $\leq 0.6 \%$ ) indicates that outcome with computed tomography is not 
Table 1 Baseline characteristics of 2602 patients with mild head injury according to treatment group. Figures are numbers (percentages) of patients unless stated otherwise

\begin{tabular}{lccc} 
Characteristics & $\begin{array}{c}\text { Computed tomography } \\
(\mathbf{n}=\mathbf{1 3 1 6})\end{array}$ & $\begin{array}{c}\text { Observation in hospital } \\
(\mathbf{n = 1 2 8 6})\end{array}$ & Total \\
\hline $\begin{array}{l}\text { Mean (SD) age } \\
\text { (years) }\end{array}$ & $30.9(22.1)$ & $32.0(22.4)$ & $31.5(22.2)$ \\
\hline Age (years): & & $442(34.4)$ & $920(35.3)$ \\
\hline $6-15$ & $478(36.3)$ & $260(20.2)$ & $533(20.5)$ \\
\hline $16-25$ & $273(20.7)$ & $237(18.4)$ & $470(18.1)$ \\
\hline $26-45$ & $233(17.7)$ & $206(16.0)$ & $403(15.5)$ \\
\hline $46-65$ & $197(15.0)$ & $141(11.0)$ & $276(10.6)$ \\
\hline$\geq 66$ & $135(10.3)$ & $752(58.5)$ & $1539(59.2)$ \\
\hline Sex: & $787(59.8)$ & $534(41.5)$ & $1063(40.8)$ \\
\hline Male & $529(40.2)$ & $341(26.5)$ & $690(26.5)$ \\
\hline Female & & $664(51.6)$ & $1345(51.7)$ \\
\hline Hospital category: & $349(26.5)$ & $281(21.8)$ & $567(21.8)$ \\
\hline University/regional & $681(51.7)$ & $2.37(3.26)$ & $2.27(3.06)$ \\
\hline Central & $286(21.7)$ & &
\end{tabular}

the observation group.

inferior to the outcome with admission for observation. In the secondary analyses we dichotomised the extended Glasgow score in all other possible ways. There were no significant differences between the groups except in one case (1-6 v 7-8), when the computed tomography method was superior (table 2 ).

As an alternative to the seven analyses of dichotomised data, we also performed a rank sum test. The outcome in the computed tomography group was slightly better than in the observation group ( $\mathrm{P}=0.062$, two sided). The worst outcomes (1-4; death to severe disability) were similarly distributed in the two groups ( $4 \% v 4.5 \%)$. Two people in the computed tomography group and one in the observation group died as a probable or possible result of the head injury $(0.2 \% v 0.1 \%)$. There were four $(0.3 \%)$ non-fatal complications in the computed tomography group and seven $(0.5 \%)$ in the observation group (table 3 ).
Table 2 Analyses of outcomes at three months in patients* with mild head injury

\begin{tabular}{|c|c|c|c|}
\hline GOS-E† & $\begin{array}{c}\text { Computed } \\
\text { tomography (\%) }\end{array}$ & $\begin{array}{l}\text { Observation in } \\
\text { hospital (\%) }\end{array}$ & $\begin{array}{c}\text { Difference }(95 \% \mathrm{Cl}) \\
(\%)\end{array}$ \\
\hline $1-7 \vee 8$ & 275 v $1010(21.4)$ & $300 \vee 940(24.2)$ & $-2.8(-6.1$ to 0.6$)$ \\
\hline $1-6 \vee 7-8$ & 112 v $1173(8.7)$ & 142 v 1099 (11.4) & $-2.7(-5.1$ to -0.4$)$ \\
\hline $1-5 \vee 6-8$ & $71 v 1213(5.5)$ & $76 \vee 1165(6.1)$ & $-0.6(-2.4$ to 1.2$)$ \\
\hline $1-4$ v 5-8 & $52 v 1235(4.0)$ & $56 v 1187$ (4.5) & $-0.5(-2.0$ to 1.1$)$ \\
\hline $1-3 \vee 4-8$ & $12 \vee 1275(0.9)$ & $7 v 1236(0.6)$ & $0.4(-0.3$ to 1.0$)$ \\
\hline $1-2$ v 3-8 & $5 \vee 1282(0.4)$ & $4 v 1240(0.3)$ & $0.1(-0.4$ to 0.5$)$ \\
\hline 1 v 2-8 & $5 \vee 1306(0.4)$ & $4 v 1275(0.3)$ & $0.1(-0.4$ to 0.5$)$ \\
\hline
\end{tabular}

*Numbers of patients in calculations differ because of missing follow-up data. †Extended Glasgow outcome scale: 1=death; 2=vegetative; 3=lower severe disability; 4=upper severe disability; $5=$ =lower moderate disability; $6=$ =upper moderate disability; $7=$ lower good recovery; $8=$ fully recovered.

Tables 4 and 5 describe cases in which patients died or underwent neurosurgical procedures. All three patients in the observation group who needed surgery had a considerable delay in diagnosis and treatment (between 43-74 days after the trauma). Although two of these patients completely recovered, earlier detection of the lesions would have been preferable in each case and possibly could have made an important difference in the one with a poor outcome.

In addition to the prespecified intention to treat analyses, we also performed per protocol analyses excluding patients who did not receive the allocated treatments as well as those who, according to inclusion and exclusion criteria, should not have been randomised. The main result was not changed: $21.3 \%$ examined with computed tomography had not recovered completely compared with $24.2 \%$ in the observation group. Similar marginal changes occurred in all other analyses.

Among the 1292 patients in the computed tomography group who underwent imaging, $6.3 \%$ had abnormal findings (table 6). On average, patients randomised to computed tomography were scanned 5.2 hours after the trauma. Nearly $28 \%$ (309/1118) of these investigations were done within three hours of the trauma. None of the patients with normal findings later developed a complication that required admission to hospital or surgery.

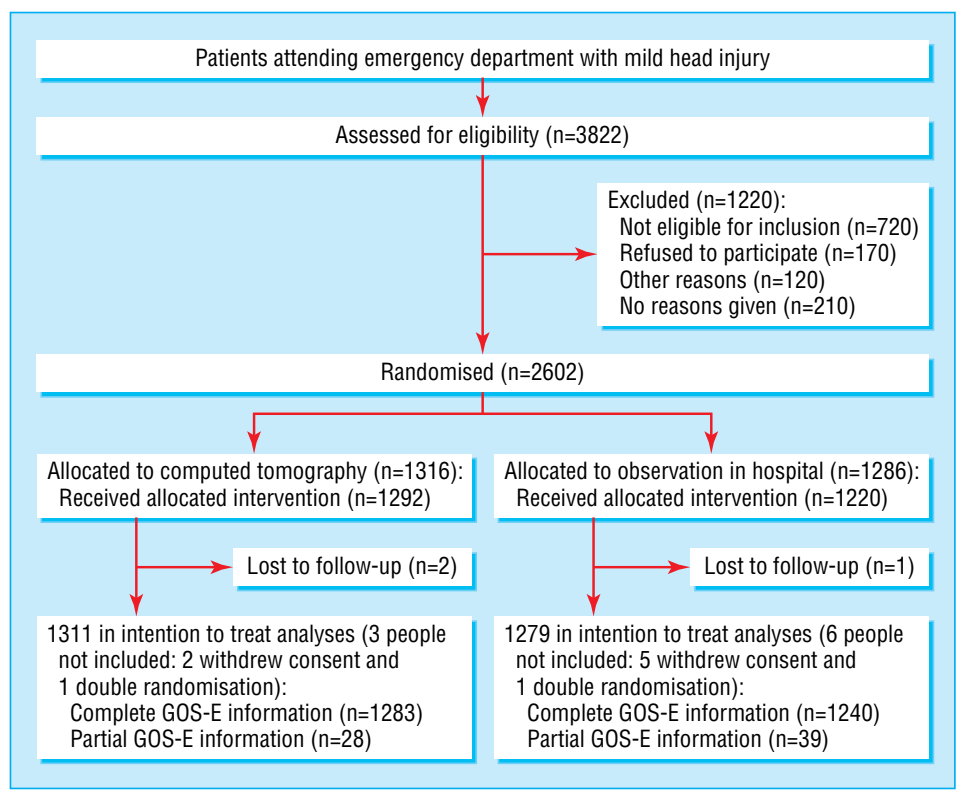

Flow of study participants (GOS-E=extended Glasgow outcome scale) 
Table 3 Death and complications according to final evaluation by blinded external and internal reviewers

\begin{tabular}{|c|c|c|c|}
\hline & $\begin{array}{l}\text { Computed } \\
\text { tomography } \\
(\mathrm{n}=1316)\end{array}$ & $\begin{array}{l}\text { Observation in } \\
\text { hospital }(n=1286)\end{array}$ & Total \\
\hline \multicolumn{4}{|l|}{ Deaths: } \\
\hline Caused by head injury & 1 & 1 & 2 \\
\hline Possibly related to head injury & 1 & 0 & 1 \\
\hline Other causes & 2 & 4 & 6 \\
\hline Total & 4 & 5 & 9 \\
\hline $\begin{array}{l}\text { Admission to ICU/neurosurgical ward } \\
\text { during acute phase }\end{array}$ & 2 & 3 & 5 \\
\hline \multicolumn{4}{|l|}{ Neurosurgical operations: } \\
\hline -During acute phase & 0 & 0 & 0 \\
\hline During three month follow-up & 1 & 3 & 4 \\
\hline \multicolumn{4}{|l|}{ Readmissions: } \\
\hline $\begin{array}{l}\text { Readmission due to symptoms of } \\
\text { head injury }\end{array}$ & 1 & 1 & 2 \\
\hline
\end{tabular}

Patients' satisfaction was similar in both groups: $92.5 \%$ in the computed tomography group and $93.8 \%$ in the observation group were satisfied or quite satisfied with the care they had received.

\section{Exceptions to follow-up}

Only three patients were completely lost to follow-up. They were foreign citizens and could not be reached despite considerable efforts. None had complications in the acute phase, and all were
Table 6 Abnormal findings on computed tomography and time between trauma and scan in participants allocated to immediate computed tomography

\begin{tabular}{lc}
\hline \multicolumn{1}{l}{ Data $(\%)$} \\
\hline Abnormality ${ }^{*}$ Caused by acute injury & $39(3.0)$ \\
\hline Unclear if result of acute injury & $13(1.0)$ \\
\hline Not correlated to acute injury & $30(2.3)$ \\
\hline Total & $82(6.3)$ \\
\hline Time between trauma and scan (hours) $\dagger:$ & $73(6.5)$ \\
\hline$<2$ & $236(21.1)$ \\
\hline $2-3$ & $809(72.4)$ \\
\hline$>3$ & $5.2(0.7-29.25)$ \\
\hline Mean (range)
\end{tabular}

\section{*Data from 1292 patients.}

tData from 1118 patients.

well at discharge. Seven patients, all well at discharge, withdrew consent to take further part in the study. Nine patients had mild head injury twice and were randomised twice. For seven of them, the second injury occurred more than three months after the first, and these patients were counted as 14 cases. For two patients, however, the two events occurred within less than three months, and we included only the second randomisation in the analyses. Sixty five patients could not be included in the main analysis because we had only partial information on extended Glasgow score: 59 patients could not be reached by regular follow-up (all were registered as alive in the national population

Table 4 Case descriptions of all deaths within three months of index trauma (final interpretation of cause of death according to blinded external and internal reviewers)

\begin{tabular}{|c|c|c|c|c|c|}
\hline Patient with history & Randomisation & $\begin{array}{l}\text { Initial hospital episode and subsequent care of } \\
\text { injury }\end{array}$ & $\begin{array}{l}\text { Cause of death (on } \\
\text { death certificate) }\end{array}$ & $\begin{array}{l}\text { Death related to } \\
\text { head injury }\end{array}$ & $\begin{array}{l}\text { Time between injury and } \\
\text { death (days) }\end{array}$ \\
\hline $\begin{array}{l}\text { Man aged } 84 \text {, taking warfarin, fell } \\
\text { at home }\end{array}$ & $\begin{array}{l}\text { Computed } \\
\text { tomography }\end{array}$ & $\begin{array}{l}\text { Subdural haematoma, admitted to surgical ward, } \\
\text { worsening medical condition, no operation }\end{array}$ & Subdural haematoma & Yes & 5 \\
\hline $\begin{array}{l}\text { Woman aged 92, heart failure and } \\
\text { osteoporosis, fell at home }\end{array}$ & $\begin{array}{l}\text { Computed } \\
\text { tomography }\end{array}$ & $\begin{array}{l}\text { No initial CT as a result of poor compliance, } \\
\text { observation overnight because of vomiting. No } \\
\text { additional care }\end{array}$ & $\begin{array}{l}\text { Cardiosclerosis and } \\
\text { heart failure }\end{array}$ & Unclear & 11 \\
\hline $\begin{array}{l}\text { Man aged } 76 \text {, metastasised } \\
\text { prostate cancer, fell at home }\end{array}$ & $\begin{array}{l}\text { Computed } \\
\text { tomography }\end{array}$ & $\begin{array}{l}\text { Normal CT result, admitted to urology ward for } \\
\text { social reasons. No additional care }\end{array}$ & $\begin{array}{l}\text { Metastasised prostate } \\
\text { cancer }\end{array}$ & No & 24 \\
\hline $\begin{array}{l}\text { Woman aged } 77 \text {, healthy, fell at } \\
\text { home }\end{array}$ & $\begin{array}{l}\text { Computed } \\
\text { tomography }\end{array}$ & $\begin{array}{l}\text { Normal CT result, not admitted. Persistent } \\
\text { headache/dizziness, died suddenly. Autopsy } \\
\text { diagnosis }\end{array}$ & $\begin{array}{l}\text { Subarachnoid } \\
\text { haemorrhage }\end{array}$ & No & 24 \\
\hline $\begin{array}{l}\text { Man aged } 93 \text {, healthy, cycling } \\
\text { when hit by car }\end{array}$ & $\begin{array}{l}\text { Computed } \\
\text { tomography }\end{array}$ & $\begin{array}{l}\text { Normal CT result, hip fracture, admitted to } \\
\text { orthopaedic ward. No additional care }\end{array}$ & Perforated ulcer & No & 56 \\
\hline $\begin{array}{l}\text { Man aged } 80 \text {, hypertension, hit by } \\
\text { car at low speed }\end{array}$ & Observation & $\begin{array}{l}\text { CT after } 3 \text { hours because of confusion. Subdural } \\
\text { haematoma and skull fracture. Observed in } \\
\text { ICU/surgical ward, worsening medical condition, } \\
\text { no operation }\end{array}$ & $\begin{array}{l}\text { Subdural haematoma } \\
\text { with skull fracture }\end{array}$ & Yes & 13 \\
\hline $\begin{array}{l}\text { Woman aged } 57 \text {, recently } \\
\text { diagnosed ALS, fell at home }\end{array}$ & Observation & $\begin{array}{l}\text { Uncomplicated observation for two days, no CT. } \\
\text { No additional care }\end{array}$ & Myocardial infarction & No & 41 \\
\hline $\begin{array}{l}\text { Woman aged } 75 \text {, heart failure, fell } \\
\text { at home }\end{array}$ & Observation & $\begin{array}{l}\text { Uncomplicated observation overnight, no CT. No } \\
\text { additional care }\end{array}$ & Coronary heart disease & No & 85 \\
\hline $\begin{array}{l}\text { Woman aged } 86 \text {, metastatic } \\
\text { cancer, fell at home }\end{array}$ & Observation & $\begin{array}{l}\text { Uncomplicated observation for five days, no CT. } \\
\text { No additional care }\end{array}$ & Metastasised cancer & No & 60 \\
\hline
\end{tabular}

$\mathrm{CT}=$ computed tomography; ALS=amyotrophic lateral sclerosis.

Table 5 Case descriptions of all neurosurgical procedures in study

\begin{tabular}{|c|c|c|c|c|c|}
\hline Patient, history & Randomisation & $\begin{array}{l}\text { Initial hospital episode and } \\
\text { subsequent care of injury }\end{array}$ & $\begin{array}{l}\text { Reason for second visit to hospital, } \\
\text { CT finding }\end{array}$ & $\begin{array}{l}\text { Time between injury } \\
\text { and surgery (days) }\end{array}$ & $\begin{array}{l}\text { Outcome at three } \\
\text { months (GOS-E) }\end{array}$ \\
\hline $\begin{array}{l}\text { Man aged } 58, \text { healthy, fell down } \\
\text { stairs }\end{array}$ & Computed tomography & $\begin{array}{l}\text { Normal CT, not admitted. No additional } \\
\text { care }\end{array}$ & New head injury, subdural haematoma & 89 & 7 \\
\hline Man aged 63 , healthy, fell on ice & Observation & $\begin{array}{l}\text { Uncomplicated observation overnight, } \\
\text { no CT. No additional care }\end{array}$ & $\begin{array}{l}\text { Weakness, right sided clumsiness, } \\
\text { chronic subdural haematoma }\end{array}$ & 43 & 8 \\
\hline $\begin{array}{l}\text { Man aged } 60 \text {, hypertension, fell } \\
\text { when cycling }\end{array}$ & Observation & $\begin{array}{l}\text { Uncomplicated observation overnight, } \\
\text { no CT. No additional care }\end{array}$ & $\begin{array}{l}\text { Progressive headache, fell from ladder, } \\
\text { chronic subdural haematoma }\end{array}$ & 47 & 8 \\
\hline $\begin{array}{l}\text { Woman aged } 83 \text {, hypothyroidism, } \\
\text { cycling when hit by car }\end{array}$ & Observation & $\begin{array}{l}\text { Uncomplicated observation overnight, } \\
\text { no CT. No additional care }\end{array}$ & $\begin{array}{l}\text { Dizziness, memory problems, chronic } \\
\text { subdural haematoma }\end{array}$ & 74 & 4 \\
\hline
\end{tabular}

GOS-E=extended Glasgow outcome scale; CT=computed tomography 
register and had no further care in hospital for head trauma within three months), and six submitted incomplete follow-up data and could not be reached to complete the assessment. In 26 cases, the randomised patients were not fully eligible (10 in the computed tomography group and 16 in the observation group). All patients were included in the intention to treat analysis (2590, $99.5 \%$, (figure).

\section{Exceptions to protocol}

Two causes contributed to the difference in group sizes (30 cases fewer in the observation group). An error by the statistician in the preparation of the randomisation sequence for one of the centres explains a difference of 12. Furthermore, when all unused envelopes were returned after the end of the study, 55 were missing: 20 from the computed tomography group and 35 from the observation group. The difference was possibly because patients in the observation group are often transferred from the emergency department to an inpatient ward, thereby increasing the risk that the case report form becomes hidden in the case notes. Even if we add 20 not completely recovered patients to the computed tomography group and 35 completely recovered to the observation group, the computed tomography strategy is still not inferior in the sense we have defined.

\section{Discussion}

In this large pragmatic randomised trial of computed tomography compared with observation in hospital in patients with mild head injury we found that, in various clinical settings and circumstances, the computed tomography strategy is not inferior to observation as regards patients' outcomes, with similar rates of complications, mortality, and worst disabilities in the groups. The computed tomography strategy proved to be feasible, and no patients with normal findings on the scan had later complications ("false negatives"). The strategies yielded equal levels of satisfaction among patients.

We have confirmed the hypothesis that computed tomography is not inferior to observation in hospital. In fact, the prevalence of patients not fully recovered at three months was slightly lower in the computed tomography group. In the observation group there was a considerable delay in treatment in the patients who required surgery. This might have contributed to a bad outcome for one of the patients and prolonged suffering for the others.

All the patients who died or had neurosurgical procedures were in the older age groups ( $>57$ years). The current literature indicates that older people have a poorer prognosis for recovery after mild head injury. ${ }^{26}$ In a post hoc analysis of our data, we found an increasing prevalence of poor recovery according to extended Glasgow score by age, but there was equivalence between the two strategies across all age groups.

\section{Wider relevance of findings}

To assess generalisability of the findings, we compared the baseline characteristics of the randomised patients with nationwide data from all patients admitted to hospital with mild head injury in Sweden. ${ }^{28}$ We found no significant difference in age and sex and similar numbers of patients were treated in the various categories of hospital. Furthermore, participating hospitals were from different categories and from different parts of the country. Also, the pragmatic design and large size of the study showed the feasibility of the computed tomography strategy in routine health care.

We also compared our patients and their outcomes with those in other studies of mild head injury (non-randomised clinical trials). Outcome according to the extended Glasgow score at three months' follow-up was consistent with results from previous studies, although direct comparisons are difficult because of differences between the patients. ${ }^{24}{ }^{25}{ }^{29}$ Our rates of mortality, complications, and abnormal findings on computed tomography were similar to those in recent systematic reviews of mild head injury. ${ }^{30}{ }^{31}$ We therefore believe that the patients in our study were representative of patients with mild head injury, giving the results a high degree of generalisability.

In some hospitals, access to computed tomography is restricted out of office hours. Transportation difficulties and other reasons, such as elderly patients living alone, can also sometimes make observation in hospital the preferred strategy.

\section{Risks of computed tomography}

The possible risk of cancer and cognitive dysfunction in adulthood from the low dose radiation with computed tomography has been discussed. ${ }^{32}{ }^{33}$ All use of radiation in diagnostics should be guided by caution, with careful balancing of the risks and benefits. With strict adherence to the definition of mild head injury (including loss of consciousness or amnesia), the benefits probably outweigh the risk of occasional computed tomography. ${ }^{34}{ }^{35}$ Obviously, efforts should always be made to minimise unnecessary exposure to radiation without compromising image quality. ${ }^{36}{ }^{37}$

Some guidelines and clinical directives specify the number of hours after the trauma after which it is safe to discharge patients with mild head injury and normal findings on computed tomography. ${ }^{78}$ There is no evidence in the literature to support such a recommendation. ${ }^{39}$ Neither do our present results point towards the need for such a limit.

Contributors: J-LG, SO, and MB designed and planned the trial, collected and analysed the data, and wrote the paper. MB and J-LG are the guarantors.

Funding: County Council of Stockholm (Department of Research, Development, and Education); Thelma Zoéga Foundation; Apoteket; Swedish Research Council; Gorthon Foundation; Vårdal Foundation (the Swedish Foundation for Health Care Sciences and Allergy Research); Health Research Council of Southeast Sweden; Health and Medical Care Executive Board of the Region Västra Götaland; Swedish Society of Medicine; Region Skåne; and SBU (Swedish Council on Technology Assessment in Health Care).

Competing interests: None declared.

Ethical approval: The study was approved by all regional ethics committees in Sweden.

1 Peloso PM, Carroll LJ, Cassidy JD, Borg J, von Holst H, Holm L, et al. Critical evaluation of the existing guidelines on mild traumatic brain injury. J Rehabil Med 2004;43 suppl:106-12.

\section{What is already known on this topic}

Clinical management for patients with mild head injury varies

Patients are often admitted for observation and many undergo computed tomography

\section{What this paper adds}

Use of computed tomography during triage in patients with mild head injury is feasible, and clinical outcomes are similar to those in patients admitted for observation

No patient with normal findings on immediate computed tomography required intervention, despite almost half of all patients being scanned within four hours after trauma 


\section{Research}

2 De Kruijk JR, Twijnstra A, Meerhoff S, Leffers P. Management of mild traumatic brain injury: lack of consensus in Europe. Brain Inj 2001;15:117-23.

3 Blostein P, Jones SJ. Identification and evaluation of patients with mild traumatic brain injury: results of a national survey of level I trauma centers. J Trauma 2003;55:450-3.

4 Narayan RK, Michel ME, Ansell B, Baethmann A, Biegon A, Bracken MB, et al. Clinical trials in head injury. J Neurotrauma 2002;19:503-57.

5 Dickinson K, Bunn F, Wentz R, Edwards P, Roberts I. Size and quality of randomised controlled trials in head injury: review of published studies. BMJ 2000;320:1308-11.

6 Carroll LJ, Cassidy JD, Holm L, Kraus J, Coronado VG. Methodological issues and research recommendations for mild traumatic brain injury: the WHO Collaborating Centre Task Force on Mild Traumatic Brain Injury.J Rehabil Med 2004;43 suppl:113-25.

7 Jagoda AS, Cantrill SV, Wears RL, Valadka A, Gallagher EJ, Gottesfeld SH, et al. Clinical policy: neuroimaging and decision making in adult mild traumatic brain injury in the acute setting. Ann Emerg Med 2002;40:231-49.

8 Thurman D, Guerrero J. Trends in hospitalization associated with traumatic brain injury. JAMA 1999;282:954-7.

9 Livingston DH, Lavery RF, Passannante MR, Skurnick JH, Baker S, Fabian TC, et al Emergency department discharge of patients with a negative cranial computed tomography scan after minimal head injury. Ann Surg 2000;232:126-32.

10 af Geijerstam JL, Britton M, Marke LA. Mild head injury: observation or computed tomography? Economic aspects by literature review and decision analysis. Emerg Med J 2004;21:54-8.

11 Swedish Council on Technology Assessment in Health Care. Mild head injury-observation or CT-scanning? (in Swedish, summary in English at www.inahta.org). Stockholm: SBU (Swedish Council on Technology Assessment in www.inahta.org). Stockh

12 Borg J, Holm L, Peloso PM, Cassidy JD, Carroll LJ, von Holst H, et al. Non-surgical intervention and cost for mild traumatic brain injury: results of the WHO collaborating centre task force on mild traumatic brain injury.J Rehabil Med 2004;43 suppl:76-83.

13 Taylor A, Butt W, Rosenfeld J, Shann F, Ditchfield M, Lewis E, et al. A randomized trial of very early decompressive craniectomy in children with traumatic brain injury and sustained intracranial hypertension. Childs Nerv Syst 2001;17:154-62.

14 Seelig JM, Becker DP, Miller JD, Greenberg RP, Ward JD, Choi SC. Traumatic acute subdural hematoma: major mortality reduction in comatose patients treated within four hours. N Engl J Med 1981;304:1511-8.

15 Klauber MR, Marshall LF, Luerssen TG, Frankowski R, Tabaddor K, Eisenberg HM Determinants of head injury mortality: importance of the low risk patient. Neurosurgery 1989;24:31-6.

16 Rockswold GL, Pheley PJ. Patients who talk and deteriorate. Ann Emerg Med 1993;22:1004-7.

17 Jones B, Jarvis P, Lewis JA, Ebbutt AF. Trials to assess equivalence: the importance of rigorous methods. BMJ 1996;313:36-9.

18 Norlund A, Marké L-Â, af Geijerstam J-L, Oredsson S, Britton M. Cost comparison of immediate computed tomography or admission for observation after mild head injury: randomised controlled trial. $B M J$ 2006; $\mathrm{doi}=10.1136 / \mathrm{bmj} .38918 .659120 .4 \mathrm{~F}$.

19 Teasdale G, Jennett B. Assessment of coma and impaired consciousness. A practical scale. Lancet 1974;ii:81-4.

20 af Geijerstam J-L, Britton M, Mebius C. Management of minor head injuries in emergency departments in Sweden. Time for a new strategy? Eur J Surg 2000;166:526-529.

21 Wilson JT, Pettigrew LE, Teasdale GM. Structured interviews for the Glasgow outcome scale and the extended Glasgow outcome scale: guidelines for their use.J Neurotrauma 1998;15:573-85

22 Wilson JT, Edwards P, Fiddes H, Stewart E, Teasdale GM. Reliability of postal questionnaires for the Glasgow outcome scale. J Neurotrauma 2002;19:999-1005.

23 Asikainen I, Kaste M, Sarna S. Predicting late outcome for patients with traumatic brain injury referred to a rehabilitation programme: a study of 508 Finnish patients 5 years or more after injury. Brain Inj 1998;12:95-107.
24 van der Naalt J, van Zomeren AH, Sluiter WJ, Minderhoud JM. One year outcome in mild to moderate head injury: the predictive value of acute injury characteristics related o complaints and return to work.J Neurol Neurosurg Psychiatry 1999;66:207-13.

25 Thornhill S, Teasdale GM, Murray GD, McEwen J, Roy CW, Penny KI. Disability in young people and adults one year after head injury: prospective cohort study. BMJ 2000;320:1631-5.

26 Mosenthal AC, Livingston DH, Lavery RF, Knudson MM, Lee S, Morabito D, et al. The effect of age on functional outcome in mild traumatic brain injury: 6-month report of a prospective multicenter trial.J Trauma 2004;56:1042-8.

27 Susman M, DiRusso SM, Sullivan T, Risucci D, Nealon P, Cuff S, et al. Traumatic brain injury in the elderly: increased mortality and worse functional outcome at discharge despite lower injury severity. J Trauma 2002;53:219-24.

28 Peloso PM, von Holst H, Borg J. Mild traumatic brain injuries presenting to Swedish hospitals in 1987-2000. J Rehabil Med 2004;43 suppl:22-7.

29 Carroll LJ, Cassidy JD, Peloso PM, Borg J, von Holst H, Holm L, et al. Prognosis for mild traumatic brain injury: results of the WHO collaborating centre task force on mild traumatic brain injury. J Rehabil Med 2004;43 suppl:84-105.

30 Borg J, Holm L, Cassidy JD, Peloso PM, Carroll LJ, von Holst H, et al. Diagnostic procedures in mild traumatic brain injury: results of the WHO collaborating centre task force on mild traumatic brain injury.J Rehabil Med 2004;43 suppl:61-75.

31 af Geijerstam JL, Britton M. Mild head injury-mortality and complication rate: metaanalysis of findings in a systematic literature review. Acta Neurochir (Wien) 2003;145:843-50.

32 Brenner D, Elliston C, Hall E, Berdon W. Estimated risks of radiation-induced fatal cancer from pediatric CT. Am J Roentgenol 2001;176:289-96.

33 Hall P, Adami HO, Trichopoulos D, Pedersen NL, Lagiou P, Ekbom A, et al. Effect of low doses of ionising radiation in infancy on cognitive function in adulthood: Swedish population based cohort study. BMJ 2004;328:19.

34 Griffiths PD, Morrison GD. Computed tomography in children. BMJ 2004;329:930-2.

35 National Institute for Clinical Excellence. Head injury triage, assessment, investigation and early management of head injury in infants, children and adults. London: NICE, 2003 (clinical guidance 4).

36 Huda W, Lieberman KA, Chang J, Roskopf ML. Patient size and x-ray technique factors in head computed tomography examinations. I. Radiation doses. Med Phys 2004:31:588-94

37 Huda W, Lieberman KA, Chang J, Roskopf ML. Patient size and x-ray technique factors in head computed tomography examinations. II. Image quality. Med Phys 2004;31:595601.

38 Fabbri A, Servadei F, Marchesini G, Morselli-Labate AM, Dente M, Iervese T, et al. Prospective validation of a proposal for diagnosis and management of patients attending the emergency department for mild head injury. J Neurol Neurosurg Psychiatry 2004;75:410-6.

39 af Geijerstam JL, Britton M. Mild head injury: reliability of early computed tomographic findings in triage for admission. Emerg Med J 2005;22:103-7.

(Accepted 22 June 2006)

doi $10.1136 /$ bmj.38918.669317.4F

Department of Medicine, Clinical Epidemiology Unit, Karolinska University Hospital, 17176 Stockholm, Sweden

Jean-Luc af Geijerstam researcher

Emergency Department, Helsingborg Hospital, Helsingborg, Sweden

Sven Oredsson head of emergency department

Swedish Council on Technology Assessment in Health Care, Stockholm, Sweden

Mona Britton senior medical adviser

Correspondence to:J-L af Geijerstam jean-luc.af.geijerstam@ki.se 